\title{
CONTROL OF AN ELECTROMECHANICAL ACTUATOR FOR CAMLESS ENGINES
}

\author{
Chun Tai, Tsu-Chin Tsao ${ }^{1}$ \\ Department of Mechanical and Aerospace Engineering \\ University of California at Los Angeles \\ Los Angeles, CA 90095
}

\begin{abstract}
This paper presents a gray box approach for identifying physical parameters of an electromechanical actuator based on frequency response data. A feedforward and Linear-Quadratic Regulator feedback controller was developed to control the EMCV actuator for soft seating. A repetitive learning controller was designed to enhance the control performance through cycleto-cycle iterations. Experimental results achieved $0.61 \mathrm{~m} / \mathrm{s}$ valve seating speed with $0.028 \mathrm{~m} / \mathrm{s}$ standard deviation.
\end{abstract}

\section{INTRODUCTION}

Electromechanical Camless Valvetrain (EMCV) offers potential for making a high-performance engine. However, the quite-seating issue must be resolved before commercializing this product. This means that a control system is required to maintain the seating speed below a given level. The mathematical derivation in [8] revealed the instability nature of the electromechanical valve actuator regardless of the actuator design parameters. Instability leads to sensitivity to disturbance, which suggests the difficulty of using any type of open-loop control to achieve repeatable quiet-seating performance. Therefore, closedloop control is necessary in this application.

In 2000, Wang et al published a dynamic model of EMCV system. [11] In that model, the flux linkage model was assumed to have two regions, a linear region and a saturation region. Different model formats were constructed for different regions, yet only the linear region model was used for control design in later stage. Model parameters were identified for both regions with the directly measurement of electromagnetic force and valve lift. During the same year Stubbs [5] published a similar EMCV model with the variation of resistance to temperature, but only for the linear region of flux linkage. Butzmann et al [1] published an adaptive feedback control algorithm and experimental results in 2000. They demonstrated their control design on their laboratory test bench with seating velocity below $0.1 \mathrm{~m} / \mathrm{s}$. However, later Peterson et al [4] commented on this work that, "while this is effective under laboratory conditions, the authors point out potential problems when the system experiences large disturbances." In March 2001, Hoffmann and Stefanopoulou [2] published seating control design for EMCV system with position measurement. Only simulation result was published though. In June 2001, Hoffmann and Stefanopoulou published another paper [3] on ACC that includes more simulation result showing disturbance rejection of their control system. At the same conference, Tai et al [6] published modeling and soft-seating control design and experimental implementation result. The seating velocity achieved by experiment at $20 \mathrm{KHz}$ sampling rate was less than $0.05 \mathrm{~m} / \mathrm{s}$, but the transient response was oscillatory. In November 2001, Tai and Tsao [7] published their improved experimental result. The transient response became smooth and the seating velocity achieved was $0.057 \mathrm{~m} / \mathrm{s}$. One negative factor in their result is that the valve closing time was too long for high speed operation due to the weak springs they were using. In March 2002, Wang et [12] al published experimental result with seating velocity of $0.15 \mathrm{~m} / \mathrm{s}$. In June 2002, on ACC Peterson et al [4] published experimental result with seating velocity of 0.15 $\mathrm{m} / \mathrm{s}$. On the same conference, Tai and Tsao [8] published their result of $0.093 \mathrm{~m} / \mathrm{s}$ seating velocity from a modified experimental system with valve closing time comparable to those reported by Wang [12] and Peterson [4].

In this paper, repetitive learning control were implemented and different control strategies were tested, which led to reduced seating velocity of $0.061 \mathrm{~m} / \mathrm{s}$.

\section{MODEL ANALYSIS AND IDENTIFICATION}

The EMCV system is laid out as follows. Two pulse-widthmodulated (PWM) amplifiers with two DC power supplies are used to drive the two electromagnetic coils of the EMCV. The switching frequency of the amplifiers is $20 \mathrm{KHz}$. Two laser encoder sensors with resolution of $0.6328 \mu \mathrm{m}$ measure the armature and valve positions respectively. The encoder signals are fed back into a MFIO-3B DSPLink Motion Control Interface Card. Real-time control program is executed by a Texas Instrument TMS320C32 digital signal processor at $20 \mathrm{KHz}$ sampling rate, implying a velocity resolution of $0.013 \mathrm{~m} / \mathrm{sec}$ from the encoder measurement. The clock frequency of the TI DSPC32 microprocessor is $50 \mathrm{MHz}$. A PC is used to download program into DSP and upload measured data. See Figure 1.

An EMCV actuator works according to the spring-mass pendulum principle, which means that the system follows its own natural oscillation frequency, and external electromagnetic force is only needed for overcoming the friction loss. When the valveclosing event starts, the lower solenoid coil in Figure 1 is deactivated, and the valve moves up towards its seating position by the mechanical spring force. The electromechanical actuator is only effective in a relatively short range closing to the seating position, and so it is not efficient in the sense of energy consumption to apply closed-loop control when the valve is still far away from the seating position.

The voltage to current relationship, without consideration of the saturation of magnetic flux linkage, is governed by equation (1). [5]

$$
V_{s}=R i+L\left(y_{1}\right) \cdot \frac{d i}{d t}-\frac{L_{0} g i}{\left(y_{1}+d_{1}+g\right)^{2}} \cdot \frac{d y_{1}}{d t}
$$

When the armature is held still, equation (2) holds.

$$
L\left(y_{1}\right) \frac{d i}{d t}=V_{s}-R i
$$

\footnotetext{
${ }^{1}$ Corresponding author’s email: ttsao@seas.ucla.edu.
} 


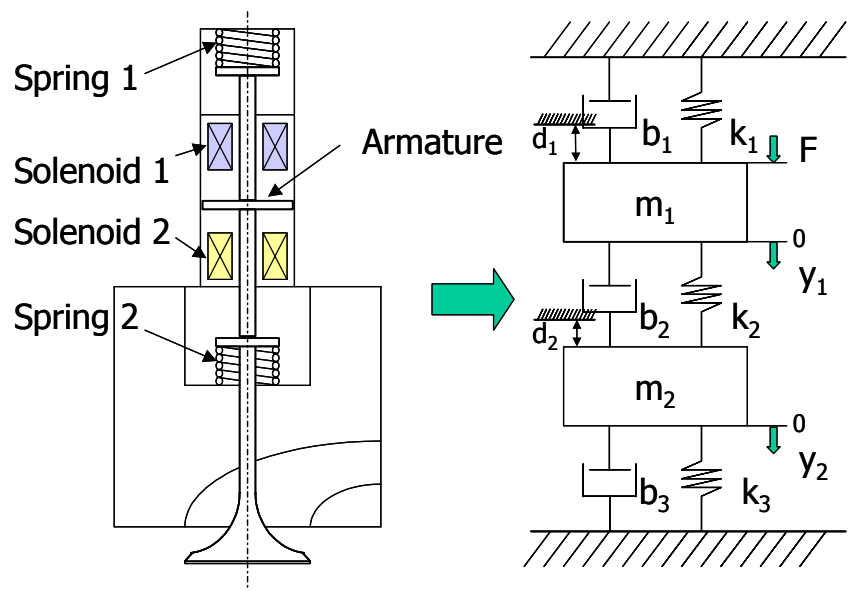

Figure 1. Schematic Diagram of EMCV System

The inductance of the coil was measured with the following procedure. At first, the two springs are removed and the armature is held at the armature seating position, i.e. $\mathrm{y}_{1}=-\mathrm{d}_{1}$. The frequency response from voltage to current is measured by sinusoidal signal sweep. The magnitude of the excitation signal is limited to be small. The frequency response was then fit by a first-order model shown in (2). The fitted curve matches with the measured data in the sense of having the same static gain and $3 \mathrm{~dB}$ frequency. Then the system is resembled and the armature is held such that the engine valve is at the mid-opening (equilibrium) position, i.e. $\mathrm{y}_{1}=0$. The frequency response from voltage to current is measured again by using the same method. The advantage of this method is that it avoids measuring force and short distance, which are difficult to gauge accurately. In addition, the values of $\mathrm{L}\left(-\mathrm{d}_{1}\right)$ and $\mathrm{L}(0)$ are different in magnitudes due to the nonlinearity of the system inductance, which leads to a precise measurement of air gap, $g$.

Based on the measurements, we may calculate $g$ and $\mathrm{L}_{0}$ by using equations (3) and (4). Table 1 lists the identified and calculated parameters in these tests.

$$
\begin{gathered}
L_{0}=L\left(-d_{1}\right) \\
g=\frac{L(0)}{L\left(-d_{1}\right)-L(0)} d_{1}
\end{gathered}
$$

Table 1. Identified Parameters from Inductance Measurements

\begin{tabular}{|l|l|}
\hline $\mathrm{L}\left(-\mathrm{d}_{1}\right)(\mathrm{H})$ & 1.25 \\
\hline $\mathrm{L}(0)(\mathrm{H})$ & 0.0770 \\
\hline $\mathrm{L}_{0}(\mathrm{H})$ & 1.25 \\
\hline $\mathrm{g}(\mathrm{mm})$ & 0.256 \\
\hline
\end{tabular}

The current-force relationship is, without consideration of the saturation of magnetic flux linkage, governed by the equation (5).

$$
F_{\text {mag }}=-\frac{L_{0} g i^{2}}{2\left(y_{1}+d_{1}+g\right)^{2}}
$$

In the next test, the armature is held at different locations by balancing the spring force with electromagnetic force. The spring force can be calculated from the spring constants and valve lift when the actuator is held still. The measured points are drawn on Figure 2 as well as equation (5).

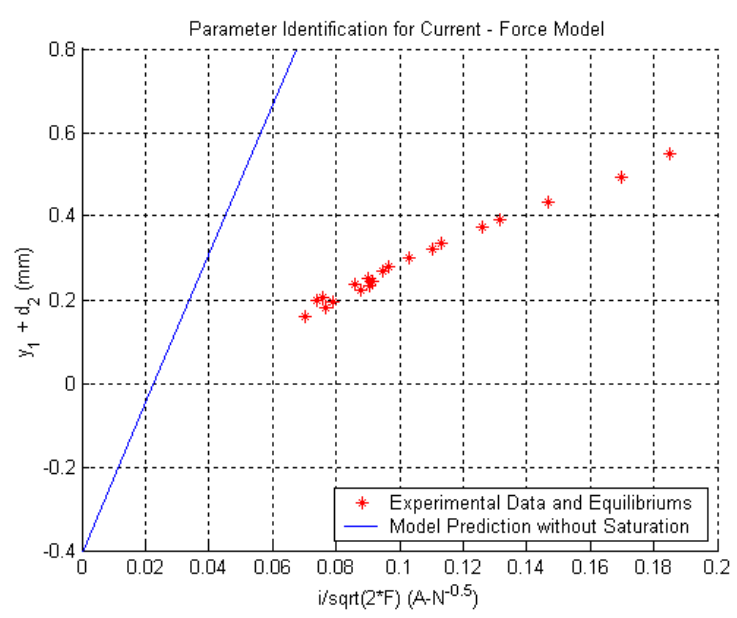

Figure 2. Comparison between Ideal Correlation and Measured Data

In the EMCV seating control, the nominal electromagnetic force for seating control is less than the spring force when the valve lift is relatively large. However, as the valve lift gets smaller and smaller, the electromagnetic force will get closer and closer to the spring force, and eventually totally balance the spring force and hold the valve at the seating position. Since almost-zero valve velocity at seating position is our control target, the system should be linearized around seating position, zero velocity and with holding current. The discrepancy between the non-saturation model and the measured data along the equilibrium points are quite significant, which indicates that equation (5) does not hold any longer for linearizing the system around seating position, zero velocity and with holding current.

To solve this problem, equation (5) is modified to reflect the effect of flux linkage saturation. See equation (6).

$$
F_{\text {mag }}=-\frac{L_{0} g i^{2}}{2\left(y_{1}+d_{1}+g\right)^{2}} \rho\left(i, y_{1}\right)
$$

By differentiating equation (6), we have

$$
d F_{\text {mag }}=G_{1} \cdot d y_{1}+G_{2} \cdot d i
$$

where

$$
\begin{aligned}
& G_{1}=\frac{L_{0} g i^{2}}{\left(y_{1}+d_{1}+g\right)^{2}}\left[\frac{\rho\left(i, y_{1}\right)}{y_{1}+d_{1}+g}-\frac{1}{2} \cdot \frac{\partial \rho\left(i, y_{1}\right)}{\partial y_{1}}\right] \\
& G_{2}=-\frac{L_{0} g i}{\left(y_{1}+d_{1}+g\right)^{2}}\left[\rho\left(i, y_{1}\right)+\frac{i}{2} \cdot \frac{\partial \rho\left(i, y_{1}\right)}{\partial i}\right]
\end{aligned}
$$

For small-signal linearization around $\mathrm{y}_{1}=\mathrm{y}_{1}{ }^{*}, \mathrm{y}_{2}=\mathrm{y}_{2}{ }^{*}$ and $\mathrm{i}$ $=i^{*}$, the transfer functions from current to armature and valve positions are shown in (10). Interested readers could refer to the author's previous paper [6] for detailed derivation.

$$
\left[\begin{array}{l}
d \bar{Y}_{1} \\
d \bar{Y}_{2}
\end{array}\right]=\frac{G_{2}^{*} \cdot\left[\begin{array}{c}
m_{2} s^{2}+\left(b_{2}+b_{3}\right) s+\left(k_{2}+k_{3}\right) \\
b_{2} s+k_{2}
\end{array}\right] \cdot d \bar{i}}{\left(m_{1} s^{2}+\left(b_{1}+b_{2}\right) s+\left(k_{1}+k_{2}-G_{1}^{*}\right)\right)\left(m_{2} s^{2}+\left(b_{2}+b_{3}\right) s+\left(k_{2}+k_{3}\right)\right)-\left(b_{2} s+k_{2}\right)^{2}}
$$

The transfer function from current to valve position can be rewritten as

$$
\frac{d Y_{2}}{d i}=\frac{B_{21} s+1}{A_{4} s^{4}+A_{3} s^{3}+A_{2} s^{2}+A_{1} s+A_{0}}
$$


where

$$
\begin{aligned}
& A_{4}=-\frac{m_{1} m_{2}\left(y_{1}^{*}+d_{1}+g\right)^{2}}{k_{2} L_{0} g i^{*}\left[\rho\left(i^{*}, y_{1}^{*}\right)+\left.\frac{i^{*}}{2} \cdot \frac{\partial \rho}{\partial i}\right|_{\left(i^{*}, y_{1}^{*}\right)}\right]} \\
& A_{3}=-\frac{\left(y_{1}^{*}+d_{1}+g\right)^{2}\left[m_{1}\left(b_{2}+b_{3}\right)+m_{2}\left(b_{1}+b_{2}\right)\right]}{k_{2} L_{0} g i^{*}\left[\rho\left(i^{*}, y_{1}^{*}\right)+\left.\frac{i^{*}}{2} \cdot \frac{\partial \rho}{\partial i}\right|_{\left(i^{*}, y_{1}^{*}\right)}\right]} \\
& A_{2}=-\frac{\left(y_{1}^{*}+d_{1}+g\right)^{2}}{k_{2} L_{0} g i^{*}\left[\rho\left(i^{*}, y_{1}^{*}\right)+\left.\frac{i^{*}}{2} \cdot \frac{\partial \rho}{\partial i}\right|_{\left(i^{*}, y_{1}^{*}\right)}\right]} \\
& \left.\cdot\left[\begin{array}{l}
m_{1}\left(k_{2}+k_{3}\right)+ \\
m_{2}\left(k_{1}+k_{2}-\frac{L_{0} g i^{* 2}}{\left(y_{1}^{*}+d_{1}+g\right)^{2}}\left[\frac{\rho\left(i^{*}, y_{1}^{*}\right)}{y_{1}^{*}+d_{1}+g}-\left.\frac{1}{2} \cdot \frac{\partial \rho}{\partial y_{1}}\right|_{\left(i^{*}, y_{1}^{*}\right)}\right.\right. \\
+\left(b_{1}+b_{2}\right)\left(b_{2}+b_{3}\right)-b_{2}^{2}
\end{array}\right]\right) \\
& A_{1}=-\frac{\left(y_{1}^{*}+d_{1}+g\right)^{2}}{k_{2} L L_{0} g i^{*}\left[\rho\left(i^{*}, y_{1}^{*}\right)+\left.\frac{i^{*}}{2} \cdot \frac{\partial \rho}{\partial i}\right|_{\left(i^{*}, y_{1}^{*}\right)}\right]} \\
& \cdot\left[\begin{array}{l}
\left(k_{1}+k_{2}-\frac{L_{0} g i^{* 2}}{\left(y_{1}^{*}+d_{1}+g\right)^{2}}\left[\frac{\rho\left(i^{*}, y_{1}^{*}\right)}{y_{1}^{*}+d_{1}+g}-\left.\frac{1}{2} \cdot \frac{\partial \rho}{\partial y_{1}}\right|_{\left(i^{*}, y_{1}^{*}\right)}\right]\right) \\
\cdot\left(b_{2}+b_{3}\right)+\left(k_{2}+k_{3}\right)\left(b_{1}+b_{2}\right)-2 b_{2}^{2}
\end{array}\right] \\
& A_{0}=-\frac{\left(y_{1}^{*}+d_{1}+g\right)^{2}}{k_{2} L_{0} g i^{*}\left[\rho\left(i^{*}, y_{1}^{*}\right)+\left.\frac{i^{*}}{2} \cdot \frac{\partial \rho}{\partial i}\right|_{\left(i^{*}, y_{1}^{*}\right)}\right]} \\
& \cdot\left[\left(k_{1}+k_{2}-\frac{L_{0} g i^{* 2}}{\left(y_{1}^{*}+d_{1}+g\right)^{2}}\left[\frac{\rho\left(i^{*}, y_{1}^{*}\right)}{y_{1}^{*}+d_{1}+g}-\left.\frac{1}{2} \cdot \frac{\partial \rho}{\partial y_{1}}\right|_{\left(i^{*}, y_{1}^{*}\right)}\right]\right)\left(k_{2}+k_{3}\right)-k_{2}^{2}\right]
\end{aligned}
$$

$A_{0}, A_{1}, A_{2}, A_{3}$ and $A_{4}$ can be identified by curve-fitting with frequency response test data. There are seven unknown parameters in these equations, $\rho\left(i^{*}, y_{1}^{*}\right),\left.\frac{\partial \rho}{\partial i}\right|_{\left(i^{*}, y_{1}^{*}\right)},\left.\frac{\partial \rho}{\partial y_{1}}\right|_{\left(i^{*}, y_{1}^{*}\right)}, \mathrm{b}_{1}$, $b_{2}, b_{3}, k_{2}$. Two more equations are needed to solve for the unknown parameters, which are

$$
\begin{gathered}
\rho\left(i^{*}, y_{1}^{*}\right)=-\frac{2\left(y_{1}^{*}+d_{1}+g\right)^{2}\left(k_{1}+k_{3}\right) y_{1}^{*}}{L_{0} g i^{* 2}} \\
b_{1}+b_{3}=b
\end{gathered}
$$

where $b$ is the damping coefficient identified from the free response test, and $\mathrm{F}^{*}$ is the balanced spring force at equilibrium position.

Frequency response tests were conducted on the experimental system to extract the unknown parameters in (10) (18). The open-loop system is unstable. Therefore, the identification tests had to be conducted on a closed-loop system. Chirp signal was used as the excitation signal. The reason why sinusoidal signal sweep was not used is because of the fact that it takes long time to complete a test with sinusoidal signal sweep, and during that period the temperature of the actuator increases dramatically, which adversely affects the accuracy of the result. Data were recorded around three different armature positions.
The regulated positions of these three runs are $0.3,0.5$ and 0.7 mm, respectively. The identified parameters are listed in Table 2.

Table 2. Parameters Identified from Closed-Loop Frequency Response Test

\begin{tabular}{|l|l|}
\hline Spring constant $\mathrm{k}_{2}(\mathrm{kN} / \mathrm{m})$ & 751.6 \\
\hline Damping coefficient, $\mathrm{b}_{1}(\mathrm{~kg} / \mathrm{sec})$ & 0.2 \\
\hline Damping coefficient, $\mathrm{b}_{2}(\mathrm{~kg} / \mathrm{sec})$ & 1.5 \\
\hline Damping coefficient, $\mathrm{b}_{3}(\mathrm{~kg} / \mathrm{sec})$ & 0.2 \\
\hline$\rho\left(i^{*}, y_{1}^{*}\right)$ & 0.092103 \\
\hline$\left.\frac{\partial \rho}{\partial y_{1}}\right|_{\left(i^{*}, y_{1}^{*}\right)}\left(\mathrm{m}^{-1}\right)$ & 172.62 \\
\hline$\left.\frac{\partial \rho}{\partial i}\right|_{\left(i^{*}, y_{1}^{*}\right)}\left(\mathrm{A}^{-1}\right)$ & -0.035199 \\
\hline
\end{tabular}

\section{CONTROL DESIGN}

The control structure is shown in Figure 3. Gp is the plant model. Gn is a notch filter. Gc is a stabilizing controller. $u_{\text {ffo }}$ is a fixed feedforward control sequence tuned offline. $u_{\mathrm{ff}}$ is the output of a repetitive learning controller.

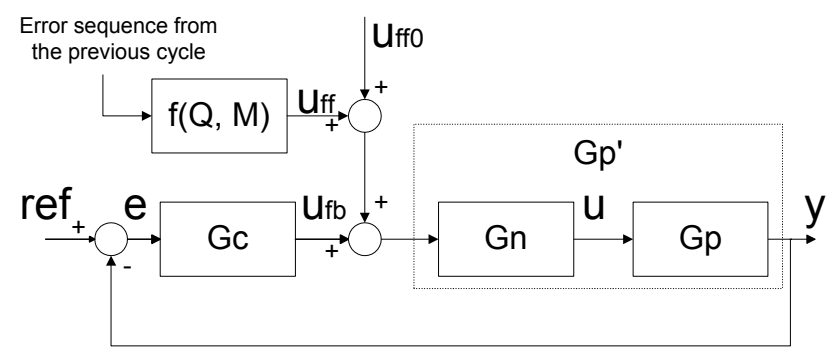

Figure 3. Control Structure

A notch filter (19) is designed to cancel the lightly-damped second-order mode (see Tai and Tsao [7]).

$$
G n(s)=\frac{\frac{s^{2}}{\bar{\omega}_{2}^{2}}+\frac{2 \zeta_{2} s}{\bar{\omega}_{2}}+1}{\frac{s^{2}}{\omega_{3}^{2}}+\frac{2 \zeta_{3} s}{\omega_{3}}+1}
$$

Ideally, $\bar{\omega}_{2}$ should be equal to the resonant model $\omega_{2}$ for perfect cancellation. However, in real implementation, $\bar{\omega}_{2}$ should be set to be a little bit smaller than $\omega_{2}$ for the robustness of design. The importance of having this notch filter is demonstrated in Tai and Tsao [7].

The notch filter needs to be discretized for the experimental implementation. Discretizing the notch filter using bilinear transformation with frequency pre-warping will get rid of the frequency distortion at notch frequency. The formula of bilinear transformation with frequency pre-warping at $\omega^{*}$ is shown in (20).

$$
s \rightarrow \frac{\omega^{*}}{\tan \left(\frac{\omega^{*} T}{2}\right)} \cdot \frac{z-1}{z+1} \text { i.e. } C(z)=\left.C(s)\right|_{s \rightarrow \frac{\omega^{*}}{\tan \left(\frac{\omega^{*} T}{2}\right)} \cdot \frac{z-1}{z+1}}
$$

An experimental test was conducted to demonstrate the difference between using bilinear transformation with and without frequency pre-warping at notch frequency for the discretization of notch filter. More oscillatory response showed up in the step 
response test when no frequency pre-warping was applied. See Figure 4.

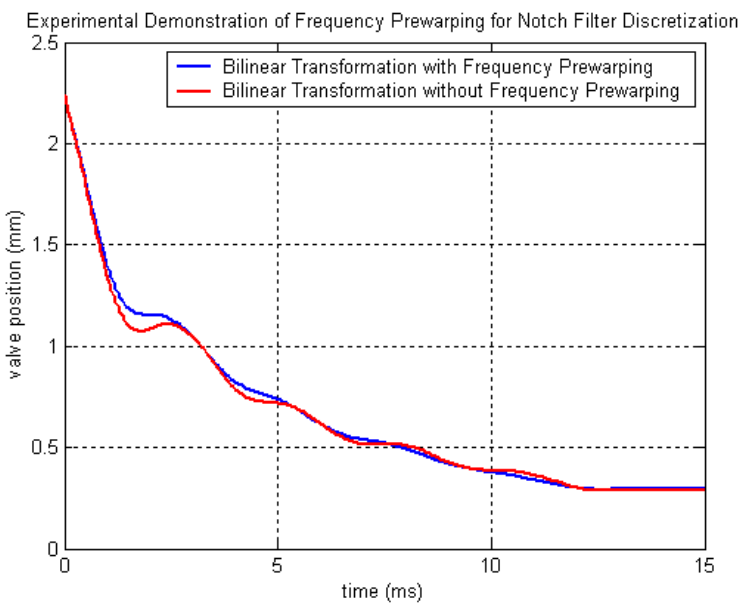

Figure 4. Experimental Demonstration of Frequency Prewarping for Notch Filter Discretization

The relatively large gain variation shown in the modeling process (see Tai and Tsao [8]) tells us that the designed control system should have relative large gain margin. Linear-quadratic optimal control design is chosen for this purpose. Please refer to [8] for the LQ optimal control design in this study. The detail of Feedforward Control Sequence and Trajectory Design is also shown in [8].

The identified plant could vary as system is in operation. It could be affected by certain factors such as temperature. Therefore, the feedforward control sequence tuned offline might need to be updated as the system is running. $n$-line. A repetitive learning controller was designed for such purpose by following the synthesis algorithm given by Tsao and Tomizuka [10]. Although it was originally formularized for repetitive feedback control design, the algorithm could also be applied for the autotuning of feedforward control signal. The closed-loop plant the repetitive learning controller "sees" is

$$
G c p=\frac{G n \cdot G p}{1+G c \cdot G n \cdot G p}
$$

The learning control for the (i+1)'th cycle is then given by

$$
u_{f f, i+1}(k)=Q \cdot\left(u_{f f, i}(k)+k_{r} \cdot M \cdot e_{i}(k)\right)
$$

where $\left\{\mathrm{e}_{\mathrm{i}}(\mathrm{k})\right\}$ is the error sequence from the $\mathrm{i}$ 'th cycle; $\left\{\mathrm{u}_{\mathrm{ff}, \mathrm{i}}(\mathrm{k})\right\}$ is the feedforward control sequence from the $i$ 'th cycle; $M$ is a stable invert of the closed-loop plant Gcp with zero phase-error; $\mathrm{k}_{\mathrm{r}}$ is a gain to adjust the converging speed; $Q$ is a low-pass filter to maintain the robust stability of the repetitive learner controller.

\section{EXPERIMENTAL RESULTS}

The closing and seating performance of the closed-loop controlled EMCV system can be quantified by using the following indices: Closing Time $t_{c}$, Seating Tail-Length $t_{s}$, Valve Seating Velocity $\mathrm{v}_{\mathrm{s}}$, and Armature Seating Velocity $\mathrm{v}_{\mathrm{a}}$. Please refer to [8] for the definitions of these performance indices.

The control design in section 3 was conducted in continuous-time domain. For experimental implementation, the notch filter was discretized by frequency pre-warping at the resonant frequency. The rest of the feedback controller was discretized with bilinear transformation at $20 \mathrm{KHz}$ sampling frequency.

The EMCV system has a natural frequency of $152 \mathrm{~Hz}$. High natural frequency is necessary for fast valve opening and closing in order to operate at high engine speeds.

It does not mean much by just having one good response because the essential problem we had at the beginning was that the system was sensitive to unknown disturbance. (Indeed, even open-loop control could occasionally render us quiet-seating performance at certain engine cycles.) Therefore when we test our control design, the most important thing is to see if we can have good and consistent system responses.

Two hundred sweeps of engine cycle tests were conducted under closed-loop control. The result of this repeatability test is shown in Figure 5 and Figure 6. Statistical analysis results were listed in Figure 7 and

Table 3. The tracking error is less than $20 \mu \mathrm{m}$.

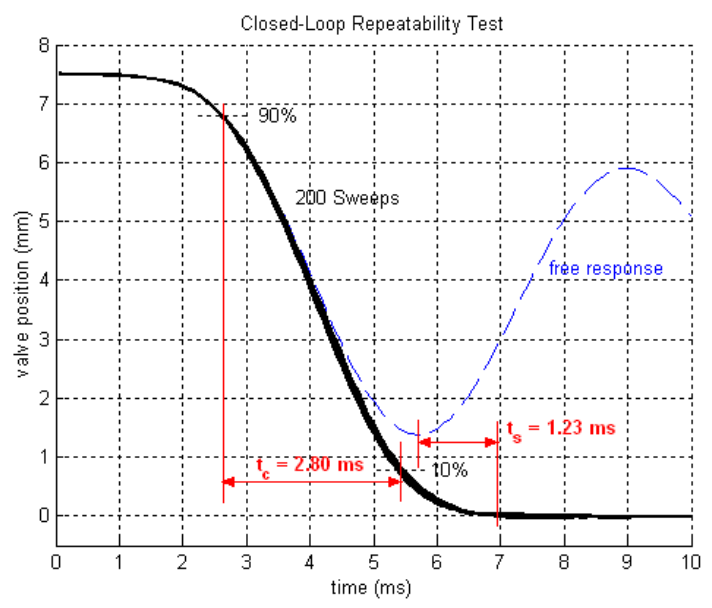

Figure 5. Closed-loop Repeatability Test for the EMCV System
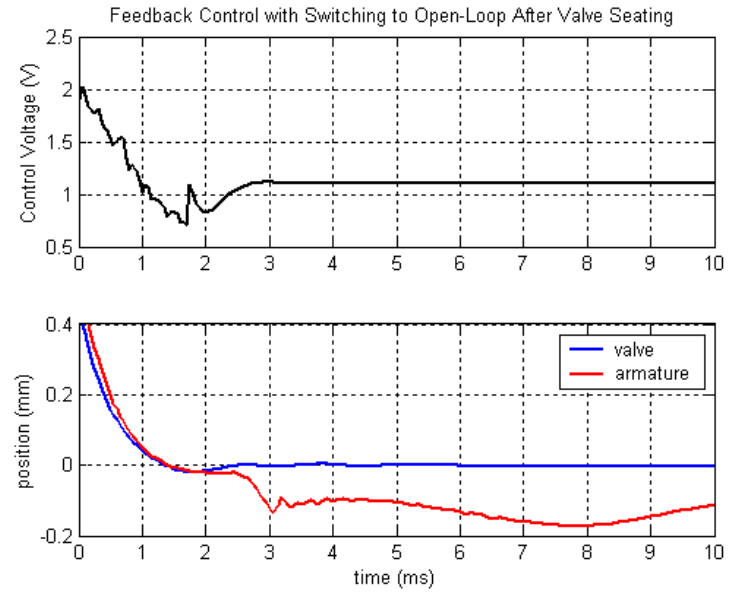

Figure 6. Feedback Control with Switching to Open-Loop After Valve Seating 


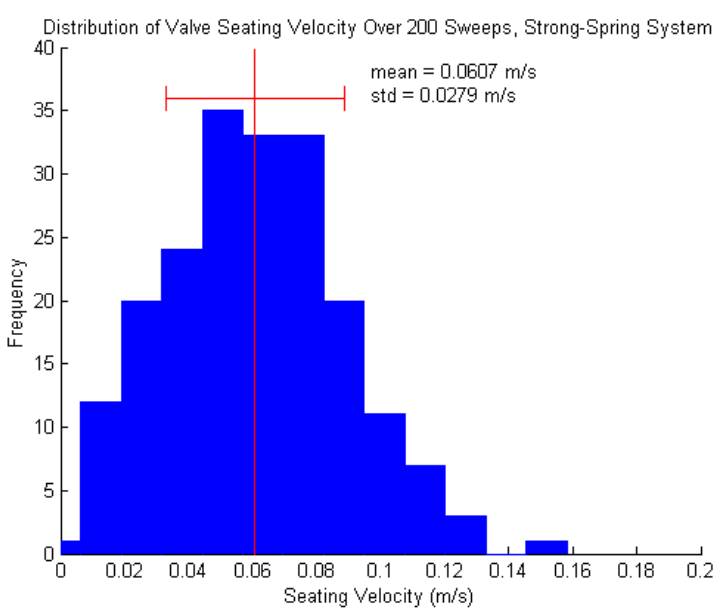

Figure 7. Distribution of Valve Seating Velocity

Table 3. Summary of Seating Control Result

\begin{tabular}{|l|l|l|}
\hline & Mean & Std. Dev. \\
\hline Valve Seating Velocity, $\mathrm{v}_{\mathrm{s}},(\mathrm{m} / \mathrm{s})$ & 0.061 & 0.028 \\
\hline Armature Seating Velocity, $\mathrm{v}_{\mathrm{s}},(\mathrm{m} / \mathrm{s})$ & 0.278 & 0.100 \\
\hline Seating Tail-Length, $\mathrm{t}_{\mathrm{s}},(\mathrm{ms})$ & 1.23 & 0.32 \\
\hline Closing Time, $\mathrm{t}_{\mathrm{c}},(\mathrm{ms})$ & 2.80 & 0.03 \\
\hline
\end{tabular}

The designed feedback controller needs to be switched to open-loop control after the valve hits its seat because after the valve hits its seat, the armature and the valve starts to separate from each other, and so the system behavior will be different. More importantly, later the armature will hit its own seat, and once it hits, the closed-loop system tends to show unfavorable performance or even turn unstable due to the severe variation of the system stiffness caused by the armature seating. See Figure 8.
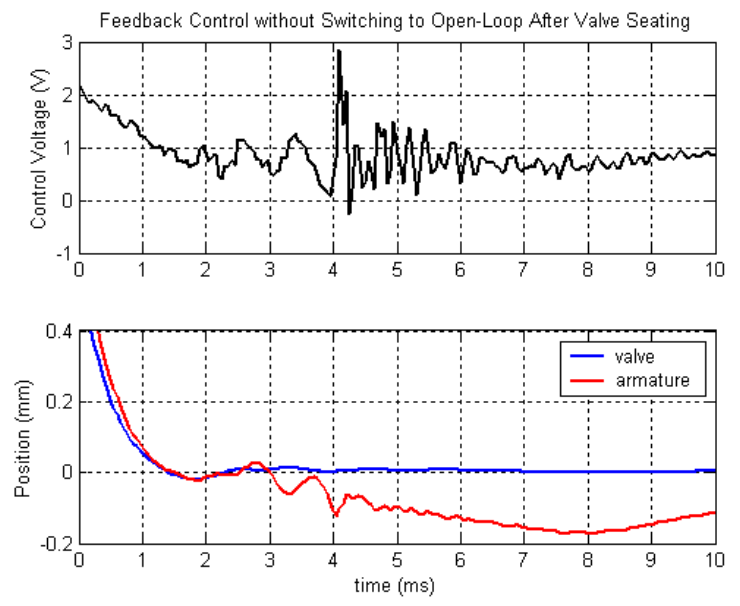

Figure 8. Feedback Control without Switching to Open-Loop After Valve Seating

It is possible to keep the closed-loop controller on without switching to open-loop control and yet without losing stability after armature and valve separates by using a low-gain feedback controller. This leads to smaller armature seating velocity $(0.048$ $\mathrm{m} / \mathrm{s}$ with standard variation of $0.029 \mathrm{~m} / \mathrm{s}$ ) but larger valve seating velocity $(0.093 \mathrm{~m} / \mathrm{s}$ with standard variation of $0.034 \mathrm{~m} / \mathrm{s})$. See
Figure 9. Since the valve seating is the main source of noise and mechanical wear, this might not be a favorable choice.

Based on the experimental results and analysis, it appears logical to use the high-gain feedback for valve soft seating and switch to the low-gain feedback for the armature soft seating. However, this approach has not been experimentally verified at this time.
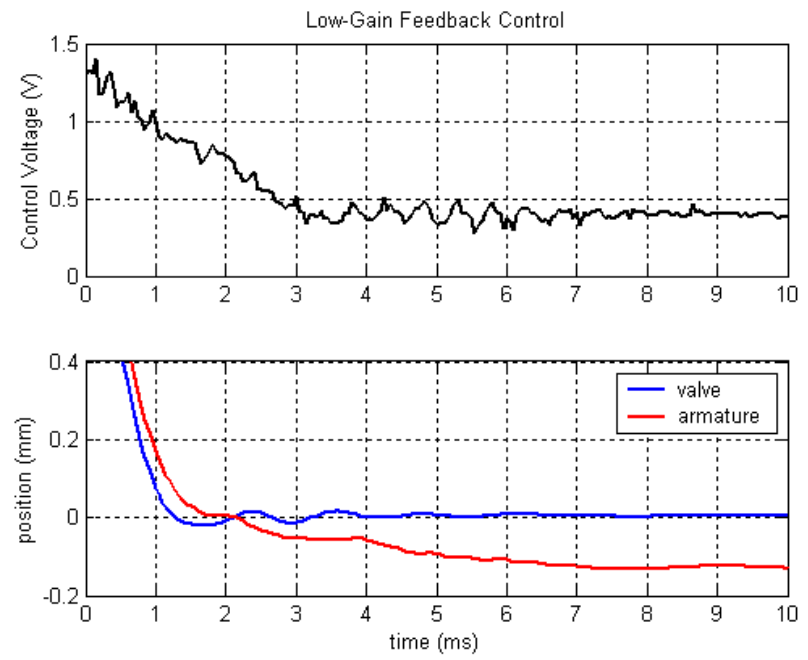

Figure 9. Low-Gain Feedback Control

In the next test, a repetitive learning controller was turned on and used to update the feedforward control based on tracking error from previous cycles. The control signal and measured outputs are drawn in Figure 10. The RMS tracking error is shown in Figure 11. The learning controller needs to be turned off after the minimum current value along the seating control trajectory reaches zero, because further iteration might cause the current go negative, which will change the polarity of the system and cause the system to be unstable.
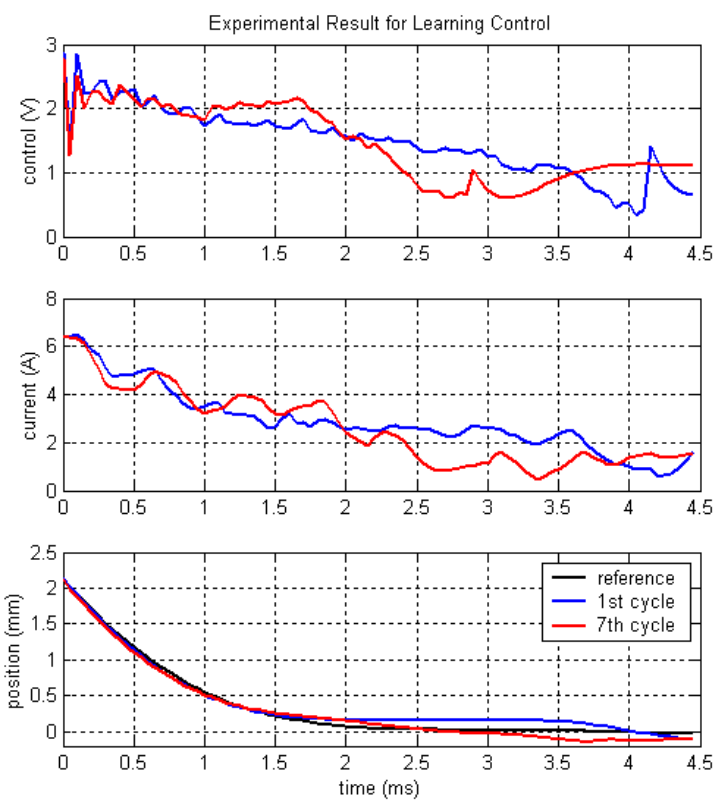

Figure 10. EMCV Learning Control 


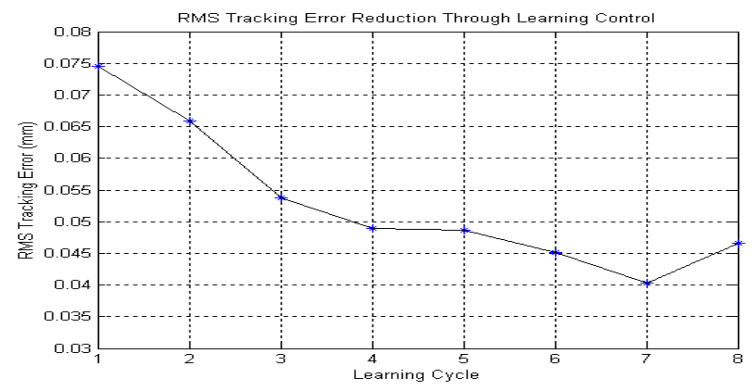

Figure 11. RMS Tracking Error Through Learning Process

\section{CONCLUSIONS}

Parameter identification was conducted for a linear EMCV actuator model. A feedback controller was designed for stabilizing the actuator by LQR control design methodology. Repetitive learning control was designed to improve tracking performance by cycle-to-cycle learning process. The different control strategies have been demonstrated on experimental systems. Valve seating velocity of $0.061 \mathrm{~m} / \mathrm{s}$ was achieved in repeatability test with a standard deviation of $0.028 \mathrm{~m} / \mathrm{s}$.

\section{ACKNOWLEDGMENT}

The authors gratefully thank Ford Research Lab for lending the electromechanical actuator and Visteon for providing the mechanical springs used in this work.

\section{REFERENCES}

[1] Butzmann, S., Melbert, J., and Koch, A., "Sensorless Control of Electromagnetic Actuators for Variable Valve Train," SAE Paper 2000-01-1225

[2] Hoffmann, W., and Stefanopoulou, A., "Valve Position Tracking for Soft Land of Electromechanical Camless Valvetrain," $3^{\text {rd }}$ IFAC Conference Advances in Automotive Control, 2001

[3] Hoffmann, W., and Stefanopoulou, A., "Iterative Learning Control of Electromechanical Camless Valve Actuator," Proceedings of the American Control Conference, Arlington, VA, June 2001

[4] Peterson, K., Stefanopoulou, A., Megli, T., and Haghgooie. M., "Output Observer Based Feedback for Soft Landing of Electromechanical Camless Valvetrain Actuator," Proc. American Control Conference, Anchorage, AK, May 8-10, 2002

[5] Stubbs, A., "Modeling And Controller Design Of An Electromagnetic Engine Valve," M.S. Thesis, University of Illinois at Urbana-Champaign, 2000

[6] Tai, C., Stubbs, A. and Tsao, T-C., "Modeling and Controller Design of an Electromagnetic Engine Valve," Proc. American Control Conference, 2890-2895, Arlington, VA, June 25-27, 2001

[7] Tai, C. and Tsao, T-C., "Quiet Seating Control Design of an Electromagnetic Engine Valve Actuator," ASME International Mechanical Engineering Congress and Exposition, New York, NY, November 11-16, 2001

[8] Tai, C. and Tsao, T-C., "Control of an Electromechanical Camless Valve Actuator," Proc. American Control Conference, 262-267, Anchorage, AK, May 8-10, 2002
[9] Tai, C., "Modeling and Control of Camless Engine Valvetrain Systems," PhD Dissertation, University of California, Los Angeles, August 2002

[10] Tsao, T-C., and Tomizuka, M., "Robust Adaptive and Repetitive Digital Tracking Control and Application to a Hydraulic Servo for Noncircular Machining," Transactions of ASME, 1994

[11] Wang, Y., Stefanopoulou, A., Haghgooie, M., Kolmanovsky, I., and Hammoud, M. "Modelling of an Electromechanical Valve Actuator for a Camless Engine," 5th International Symposium on Advanced Vehicle Control, Ann Arbor, Michigan USA, 2000

[12] Wang Y., Stefanopoulou A., Peterson K., Megli T.,Haghgooie M., "Modeling and Control of Electromechanical Valve Actuator," SAE Technical Paper 2002-01-1106, Detroit, MI, March 4-7, 2002 